\title{
Prioritizing Road Maintenance Activities using GIS Platform and Vb.net
}

\author{
Fardeen Nodrat \\ Graduate School of Engineering and Science \\ University of the Ryukyus \\ Okinawa, Japan
}

\author{
Dongshik Kang \\ Department of Information Engineering \\ University of the Ryukyus \\ Okinawa, Japan
}

\begin{abstract}
One of the most important factors for the sustainable development of any country is the quality and efficiency of its transportation system. The principled and accurate maintenance of roads, in addition to having a major impact on budget savings, improves the quality and service levels of the transportation system. For this reason, road management and maintenance are the main pillars of the transportation system in any country. Nowadays, due to the increased cost of maintaining roads and the lack of funding in this area, traditional ways of managing and maintaining roads, which are more based on the experience of the experts themselves, are no longer affordable. Hence, more recent, and more systematic methods have become more popular among relevant authorities. Afghanistan is a country facing problems such as budget deficits, lack of professional experts and advanced technology in road maintenance sector. This paper presents an example of using the GIS platform and vb.net to prioritize the road maintenance and rehabilitation activities based on identified criteria. A case study conducted in an academic environment and road maintenance and rehabilitation activities prioritized. The results show that the positive criterion has the greatest impact on the ranking of road maintenance activities. The characteristic of this process is to help the decision makers to plan road maintenance requirements to effectively and efficiently allocate funds for future planning.
\end{abstract}

Keywords-Road maintenance; prioritization; GIS; Vb.net; Technique for Order of Preference by Similarity to Ideal Solution (TOPSIS)

\section{INTRODUCTION}

Afghanistan is lacking proper road maintenance which resulted in a huge amount of investment loss in the past 10 years. The emphasis of the government and donors was on the development of new roads regardless of understanding and focusing the maintenance ability and budget. It is therefore over 4 billion USD investment in road assets is in the threat of loss. Recently the government and donors have recognized the issue and have focused to strengthen the ability in the maintenance sector. The Ministry of Public Works handles the management and development of national and regional highways. The expert staff previously existed in mentioned ministry has drastically decreased due to three decades of war. The increasing length of national and regional highways day by day is another challenge for the Government to maintain [1].

Road Maintenance is to preserve as closely as could reasonably be expected, the original designed condition of paved and unpaved roadways, and of traffic signs, signals and markings, in a manner most likely to minimize the total cost to society of vehicle operation and accident cost, in addition to the cost of giving the maintenance itself, under the requirements of serious asset confinements, in regard of skilled manpower, equipment and money, both local and foreign [2].

Pavement Management System (PMS) helps staff in assessing, tracking and grading pavement conditions in view of field examinations. The recurrence of roadway examination ranges from yearly to once like clockwork relying upon the kind of roadway. Comprehensive field assessments sort and evaluate pavement insufficiencies, for example, cracks, patches, and utility trench cuts. These inadequacies are inserted into the PMS Program that figures a Pavement Condition Index (PCI) for every roadway. PCI values extend from zero (very poor) to 100 (excellent) [3].

Priority ranking, as used as a part of PMS, is a procedure used to rank the pavement segments in a request of earnestness for maintenance and rehabilitation. The prioritization procedure is the fundamental phase of PMS before the decision makers take an official conclusion on the execution of maintenance program. The nature of Priority-setting is straightforwardly affecting the adequacy of accessible assets which are, much of the time, the essential justice of the decision maker. The priority ranking procedure relies upon different components like pavement condition, traffic volume, environmental effects, predicted execution standards, and budgetary requirements. Since maintenance activities influence the planning of work and assignment of assets, proper choice of such activities (priority) is critical to the most productive use of constrained assets [4].

In this paper, efforts have been made to prioritize roads maintenance and rehabilitation activities using the MRAP tool. With the growth of the alternatives, the measurement of problems increases respectively. This requires different mathematical operations to get the ideal answer. The advantages of MRAP tool are to simplify the prioritization process and also generate a different database for use in ArcGIS to generate thematic maps.

A case study in an academic environment was conducted in the study area. All prioritization processes were performed using the GIS platform and vb.net. The characteristic of this process is to help the decision makers to plan road maintenance requirements to effectively and efficiently allocate funds for future planning. 
The research includes the following sections: introduction, research background, introduction of prioritization approaches, introduction of TOPSIS and Shannon entropy methods, introduction of MRAP tool, data collection, calculation of criteria values, prioritization of maintenance activities using the MRAP tool, the preparation of thematic maps using GIS, results of the experiment and conclusions.

\section{LITERATURE REVIEW}

There are numerous pieces of literature studies about the prioritization strategies utilized in road maintenance sector. Each prioritization technique has diverse methods reflected by some successive steps in ranking a set of alternatives. Frequently, there are four basic steps used as a part of prioritization process as clarified below:

1) Determining the evaluation criterion.

2) Establishing performance criteria for calculating project compliance with these criteria.

3) Somehow combining the scores of each performance measurement.

4) Project rankings in order of importance.

Each strategy can't be considered to each case and place because there will be distinctive contemplations and circumstance confronted. The following are the four methods which proposed by Hudson et al.:

1) The simple subjective ranking, this technique just depends on the judgments and encounters of decision makers and can be led by utilizing matrix and decision tree. This method is a conventional strategy in which the selections of roads depend on the encounters and subjective judgments of road engineers. In this manner, it can be conducted rapidly. The subjective ranking includes a subjective evaluation of how each task is identified with objective accomplishment by deciding cost-adequacy measures of "high, medium, and low". For this situation, there is no analytical tool utilized as a part of selecting the roads to be maintained. In this manner, the needs came about tends to be predisposition and irregularity, a long way from ideal.

2) Ranking based on parameters with scoring and/or weighting, this technique is likewise straightforward, simple to utilize, and snappy yet the outcomes might be a long way from ideal. In the field of road maintenance, there are some priority evaluation scheme in creating priority rating scores as per certain numerical composite indexes, for example, defects rating index, pavement condition index, maintenance need index, rate, priority, and fuzzy condition index. In any case, a large portion of that scheme concentrates just on the pavement condition. It causes the prioritization comes about are a long way from ideal. Hence, alternate strategies utilizing multicriteria wind up well known. Ranking according to multicriteria can limit the subjective components that are overwhelming in the decision-making process for planned maintenance and can build the straightforwardness of the prioritization procedure which in the end will enhance open responsibility. Along these lines, prioritization in light of parameters is superior to anything prioritization in light of a parameter.

3) Ranking based on parameters with economic analysis, this technique is the most surely understood strategy in prioritization process since this strategy is sensibly straightforward. The decision-making devices that can be utilized as a part of this strategy are benefit/cost ratio, life cycle cost analysis, or cost-effectiveness. By and by, it changes all maintenance elements to equal money related esteems, and after that uses an economic index to assess the alternative projects with the goal that it ought to be nearer to ideal. In any case, it is hard to gauge every single pertinent effect of a project in cash terms. Along these lines, this technique needs an exhaustive investigation.

4) Optimization, this strategy is very perplexing and regularly be the most tedious technique. Then again, it has the advantages of delivering the ideal decision in which it maximizes the benefit and limits the costs. Other than that, the optimization procedure considers both time (present and future) and space (whole system).

\section{PRIORITIZATION APPROACH}

\section{A. TOPSIS Model}

The Technique for Order of Preference by Similarity to Ideal Solution (TOPSIS) is a multicriteria decision analysis method, which was originally developed by Hwang and Yoon in 1981 [5] with further developments by Yoon in 1987 [6], and Hwang, Lai and Liu in 1993 [7].

TOPSIS is based on the concept that the chosen alternative should have the shortest geometric distance from the positive ideal solution (PIS) and the longest geometric distance from the negative ideal solution (NIS) [8].

It is a method of compensatory aggregation that compares a set of alternatives by identifying weights for each criterion, normalizing scores for each criterion and calculating the geometric distance between each alternative and the ideal alternative, which is the best score in each criterion. An assumption of TOPSIS is that the criteria are monotonically increasing or decreasing. Normalization is usually required as the parameters or criteria are often of incongruous dimensions in multicriteria problems [9], [10].

Compensatory methods such as TOPSIS allow tradeoffs between criteria, where a poor result in one criterion can be negated by a good result in another criterion. This gives a more realistic form of modeling than non-compensatory methods, which include or exclude alternative solutions based on hard cutoffs [11].

The TOPSIS method evaluates the following decision matrix which has $m$ alternatives associated with $n$ attributes (or criteria): 


$$
\boldsymbol{D}=\begin{array}{cccccc}
\boldsymbol{B}_{1} & \boldsymbol{B}_{2} & & \boldsymbol{B}_{j} & & \boldsymbol{B}_{n} \\
\boldsymbol{A}_{1} \\
\boldsymbol{A}_{2} \\
\vdots \\
\boldsymbol{A}_{i} \\
\vdots \\
\boldsymbol{A}_{m}
\end{array}\left[\begin{array}{cccccc}
x_{11} & x_{12} & \ldots & x_{1 j} & \ldots & x_{1 n} \\
x_{21} & x_{22} & \ldots & x_{2 j} & \ldots & x_{2 n} \\
\vdots & \vdots & & \vdots & & \vdots \\
x_{i 1} & x_{i 2} & \ldots & x_{i j} & \ldots & x_{i n} \\
\vdots & \vdots & & \vdots & & \vdots \\
x_{m 1} & x_{m 2} & \ldots & x_{m j} & \ldots & x_{m n}
\end{array}\right]
$$

Where,

$\boldsymbol{A}_{i}=$ the $i$ th alternative considered,

$\boldsymbol{B}_{j}=$ the $j$ th criterion considered,

$x_{i j}=$ the numerical outcome of the $i$ th alternative with respect to the jth criterion.

TOPSIS assumes that each attribute in the decision matrix takes either monotonically increasing or monotonically decreasing utility. Since all criteria cannot assume to be of equal importance, the method receives a set of weights from the decision maker. For the sake of simplicity, the proposed method will be calculated as a series of steps.

\section{B. Shannon Entropy Method}

The majority of the TOPSIS applications to real-world decision-making issues use just subjective weights defined by the decision makers. Which means, a set of weights $\boldsymbol{W}=\left(w_{l}\right.$, $\left.w_{2}, \ldots, w_{j}, \ldots, w_{n}\right), \sum_{j=1}^{n} w_{j}=1$, will be determined by the decision makers. Be that as it may, when it isn't conceivable to acquire dependable subjective weights, objective weights wind up plainly helpful. One of the techniques for getting objective weights is the use of the well-known method of Shannon entropy [12].

The entropy is a term of information theory, which is otherwise called the average (expected) measure of data contained in every criterion (each column of the decision matrix (1)). The higher the value of entropy is in a specific criterion, the lower is the differences in the ratings of alternatives regarding its criterion. This, thusly, implies this criterion gives fewer data and has a little weight. So, this criterion turns out to be less important in the decision-making process. The calculation process of the Shannon entropy as below:

1) Construct the normalized decision matrix $\boldsymbol{R}=r_{i j}$,

$$
r_{i j}=\frac{x_{i j}}{\sum_{i=1}^{m} x_{i j}}
$$

Where, $i=1,2, \ldots, m$ and $j=1,2, \ldots, n$.

Note that $x_{i j}$ is the performance rating of the $i$ th alternative $A_{i}$, with respect to the $j$ th criteria $\boldsymbol{B}_{j}$ and $w_{j}$ represent the weight of the $j$ th criteria $\boldsymbol{B}_{j}$.

2) Construct the vector of the Shannon entropy $\boldsymbol{e}=\left(e_{1}, e_{2}\right.$, $\left.\ldots, e_{j}, \ldots, e_{n}\right)$

$$
e_{j}=-\frac{1}{\ln m} \sum_{i=1}^{m} r_{i j} \ln r_{i j}
$$

Where, $r_{i j} \ln r_{i j}$ is defined as 0 if $r_{i j}=0$.
3) Calculate the vector of diversification degrees $\boldsymbol{d}=\left(d_{l}\right.$, $\left.d_{2}, \ldots, d_{j}, \ldots, d_{n}\right)$,

$$
d_{j}=1-e_{j}
$$

The higher the degree $d_{j}$, the more important the corresponding criterion $\boldsymbol{B}_{j}$.

4) Calculate the vector of criteria weights $\boldsymbol{W}=\left(w_{1}, w_{2}, \ldots\right.$, $\left.w_{j}, \ldots, w_{n}\right)$,

$$
w_{j}=\frac{d_{j}}{\sum_{j=1}^{n} d_{j}}
$$

\section{MRAP Tool}

The Maintenance and Rehabilitation Activity Prioritization - MRAP Tool created using Visual Studio 2015. The main purpose of the developed tool is to prioritize maintenance and rehabilitation activities using the TOPSIS model. Initially, after data entry, the tool performs the entire computing process, which is TOPSIS method and provides the user with an optimized prioritization table. While this tool prioritizes the alternatives, hence, there must be at least two alternatives with at least two criteria to use this tool. Fig. 1 shows the main screen of the tool.

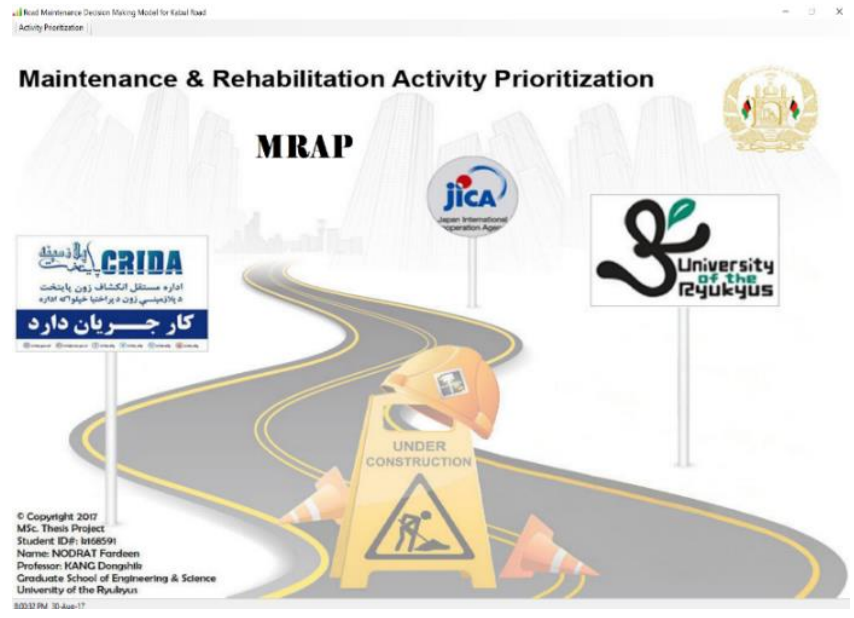

Fig. 1. MRAP tool main window.

\section{STUDY AREA}
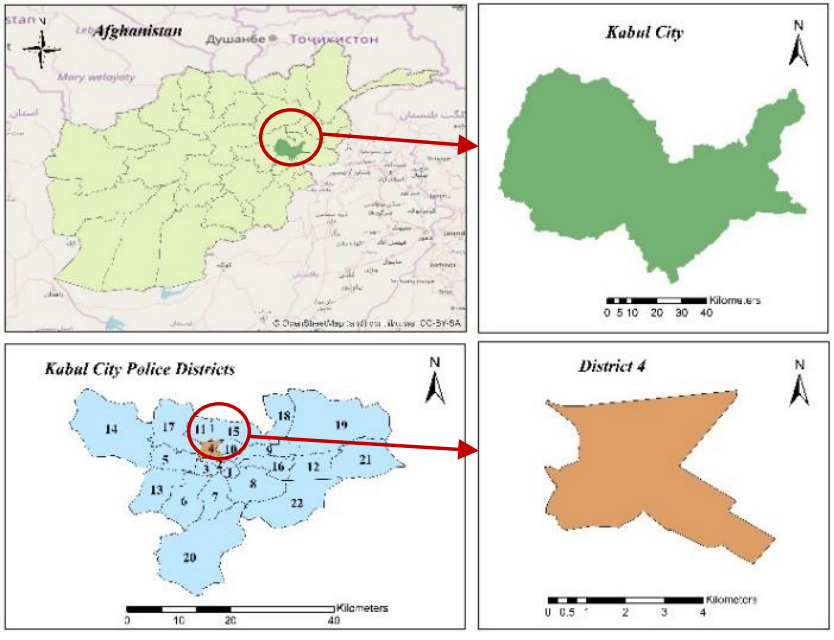

Fig. 2. Study area. 
The study area covers District 4 of Kabul city. In the capital, the main residential area districts are, districts 4, 6, 11, 14,16 respectively, and some suburban area outside of Kabul, the commercial districts are districts $1,2,3,7,9$ and 10. Thus, many of the business and residential districts are located on the opposite side of the city. Because the accessibility from the west to the east is limited by only four streets, they experience significant congestion [13].

The District 4 constitutes the main extension area of the city center. The suburbanization has been continuing northwestward along Salang Watt Street from District 2 and further into District 17. This district is bordered on the planned residential areas of District 11 and District 15 to the north, and District 10 to the east [14].

The District 4 has a land area of $11.63 \mathrm{~km} 2$, of which $83.1 \%$ is an urban area. Moreover, $54.2 \%$ of the urban area is of high density. District 4 is, in fact, the most densely developed and populated of all the districts in the city. The district has small agricultural land covering 11.5 ha or $1.0 \%$ of the district land for rain-fed agriculture and orchards. Vacant land occupies only $6.0 \%$ due to the hills along the southwestern border. The Macro-rayon housing complex occupies 6.6 ha. Lively formal and informal markets are found in the suburbanized area along the main street. Fig. 2 shows the location of our study area.

\section{DATA COLLECTION}

\section{A. Data Requirements}

The next step in the preparation phase is the identification of the data requirements. All data related to research needs have been collected and extracted in connection with the achievement of research aims. Data types are:

- Road general data

- Road engineering data

- Traffic volume

- Pavement condition index

- Road maintenance data

- Road distress information data

\section{B. Required Tools}

In this study, we collected and extracted data through government agencies, via the Internet, and field surveys. Due to the lack of resources in government agencies, we must extract some data from the Internet. The following tools are used to conduct field surveys and collect physical road data as well as collect and extract data in order to achieve the research goals:

- Survey datasheet

- Tape meter

- Digital camera

- Laptop

- Internet
- Paver 5.2 (demo version)

- MRAP tool

- ArcGIS 10.4

\section{Road Engineering Data}

We collected and extracted the location map and the base map of the study area from the Kabul Municipality and the Internet (basically Google Earth and OpenStreetMap). Fig. 3 shows the location and base map in our study area.

Road engineering data is usually included (road name, section name, width, length, type of surface, classification, traffic volume, ..., etc.). We collected key road information from the Kabul Municipality, as well as extracted some physical road information from the Internet. The basic information about our study area is shown in Table I. Fig. 4 shows the illustration of our study area.

TABLE I. ROADS ENGINEERING INFORMATION

\begin{tabular}{|c|c|c|c|c|c|}
\hline ID & Road's name & Sec. & Width & Length & Surface \\
\hline 1 & Shahid Rd & 1 & 10 & 207 & Asphalt \\
\hline 2 & Shahid Rd & 2 & 10 & 214 & " \\
\hline 3 & Sulh Rd & 1 & 10 & 132 & " \\
\hline 4 & Sulh Rd & 2 & 10 & 116 & " \\
\hline 5 & Sulh Rd & 3 & 10 & 126 & " \\
\hline 6 & Kulola Pushta Rd & 1 & 10 & 135 & " \\
\hline 7 & Kulola Pushta Rd & 2 & 10 & 158 & " \\
\hline 8 & Kulola Pushta Rd & 3 & 10 & 131 & " \\
\hline 9 & Shahr e Naw St & 1 & 7.5 & 131 & " \\
\hline 10 & Shahr e Naw St & 2 & 7.5 & 83 & " \\
\hline 11 & Shahr e Naw St & 3 & 7.5 & 78 & " \\
\hline 12 & Shahr e Naw St & 4 & 7.5 & 127 & " \\
\hline 13 & Ansari $1 \mathrm{St}$ & 1 & 8.5 & 209 & " \\
\hline 14 & Ansari $1 \mathrm{St}$ & 2 & 8.5 & 204 & " \\
\hline 15 & Ansari $2 \mathrm{St}$ & 1 & 8.5 & 211 & " \\
\hline 16 & Ansari $2 \mathrm{St}$ & 2 & 8.5 & 205 & " \\
\hline 17 & Ansari $3 \mathrm{St}$ & 1 & 8.5 & 211 & " \\
\hline 18 & Ansari $3 \mathrm{St}$ & 2 & 8.5 & 205 & $"$ \\
\hline 19 & Ansari $4 \mathrm{St}$ & 1 & 10 & 206 & " \\
\hline 20 & Ansari $4 \mathrm{St}$ & 2 & 10 & 208 & $"$ \\
\hline
\end{tabular}




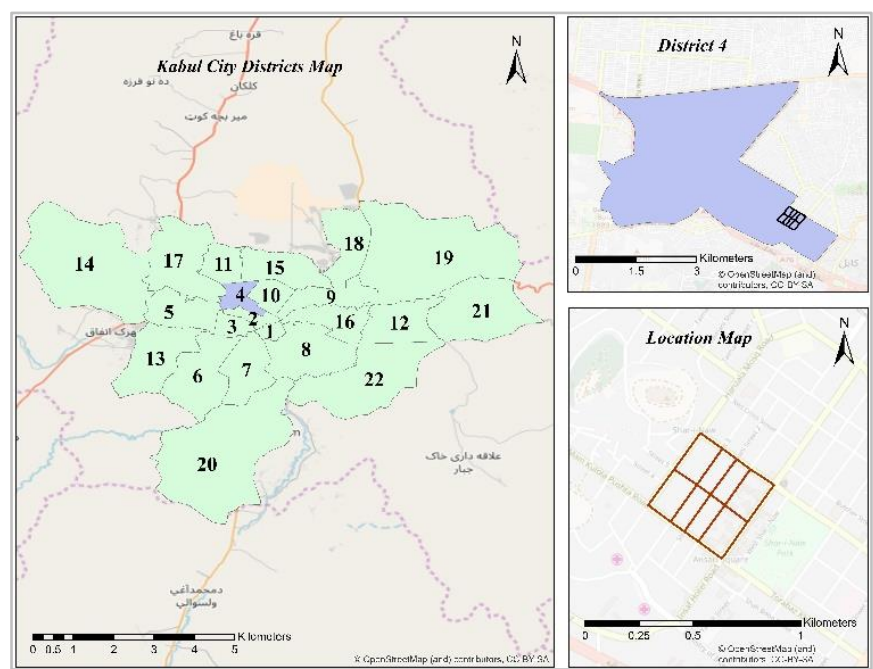

Fig. 3. Location and base map.

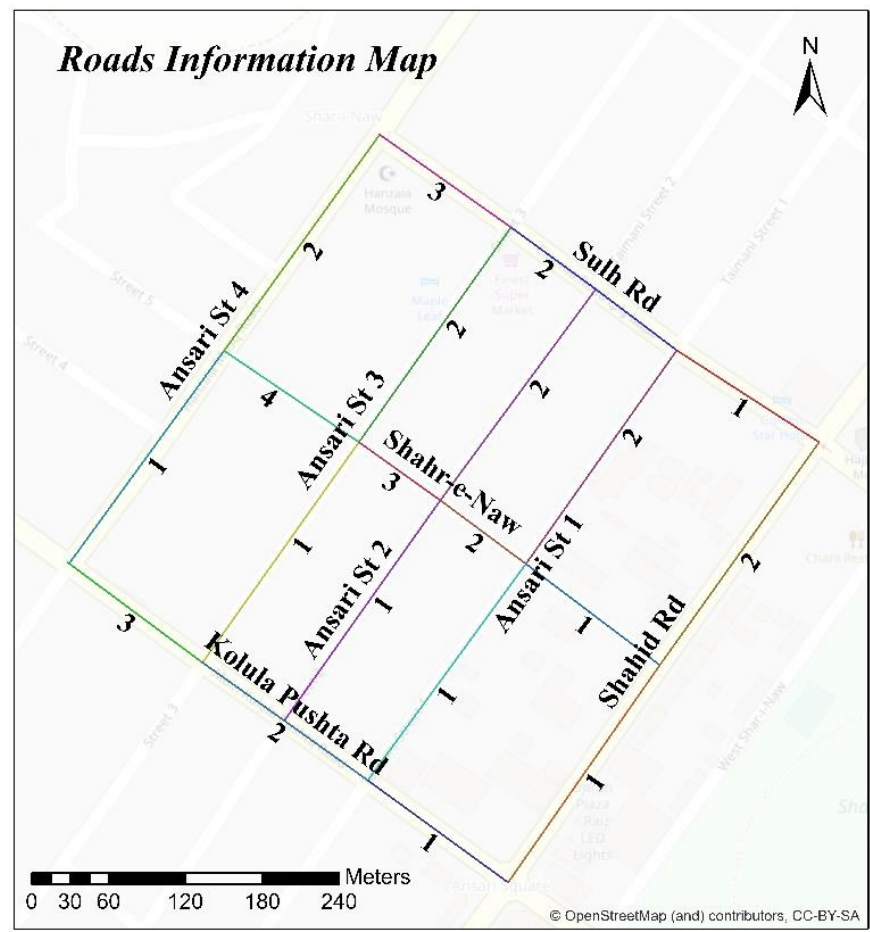

Fig. 4. Roads information map.

\section{Fieldworks}

Basically, the fieldwork involves a visual inspection of road distresses to calculate the PCI. To carry out the inspection activities, we prepared a survey datasheet based on the TM 5623 form of Corps of Engineering. In the first step, after identifying the distress, we collected all the measurements (Length, area, severity, ... etc.), and then the results were included in pre-prepared forms.

\section{MATERIAL AND METHOD}

\section{A. Criteria Values Calculations}

After research and studies and discussing with road maintenance experts, we have identified the following criteria for prioritizing the road maintenance and rehabilitation activities in the study area:

1) Pavement condition index

2) Traffic volume

3) Roads width

4) Political, social and cultural importance factor (IF)

5) Maintenance and rehabilitation cost

It should be noted that from the above criteria the 1-4 criteria are positive (+) and the fifth criteria are the negative (-) criteria. That means, in the positive criteria, the highest quantities have the highest priority, such as PCI. But in the negative criteria, the situation is quite the opposite. That is, in the negative criteria, the higher the number, the lower the priority.

The next step is to find the values for all the abovementioned criteria to prepare the decision matrix.

1) Pavement condition index (PCI):

We used the Paver 5.2 (Demo version) for calculation of the PCI. After we collected the road distresses physical information, we enter those data into the Paver software, and we can easily calculate the PCI, which is a numeric value from 0-100 and the highest values show the road with good condition. As all the road constructed in 2014 so there are no major problems and based on the PCI values it shows all the roads are in good conditions with minor treatments.

2) Traffic volume:

According to a $2005 \mathrm{Kabul}$ vehicle census, a total of 341,047 vehicles is registered consisting of mostly small cars (66.2\%) followed by trucks. The previous 2004 percentages were approximately $49 \%$ passenger cars, $20 \%$ trucks, $15.5 \%$ motorcycles, $10 \%$ buses, $3 \%$ foreign vehicles and $1.5 \%$ rickshaws. The vehicle population increases by approximately $11 \%$ annually. Illegal importation of used vehicles is a major problem in the country. It is estimated that about 300,000 of these vehicles exist and most of them are in Kabul. The United Nations Integrated Regional Information Networks (IRIN) reports that every month 8,000 new vehicles are registered with the Kabul Traffic Department, adding to Kabul's one million vehicles. This report estimated 1,224,000 vehicles as of 2010 . The narrow roadways of Kabul, built more than three decades ago are now a victim of massive traffic. The road system of Kabul was originally designed for only 25,000 to 35,000 vehicles a day and is not sufficient for the rapidly increasing number of vehicles. There is also no ring road to support the dense traffic in the city center [14]. We collected the traffic volume (TF) data from Capital Region Independent Development Authority - CRIDA.

3) Roads width:

We collected all road width from the Kabul Municipality.

4) Political, social and cultural importance factor:

In this research, the political, social \& cultural importance factor in the study area, was measured through the expert views. We asked 10 experts in this area to give numbers 1 to 10 for all our study area based on their political, social and cultural aspects. Then we calculated the important factor (IF) 
for all the road sections using the MS Excel, by averaging all the factor values.

5) Maintenance and rehabilitation cost:

For calculating the maintenance and rehabilitation cost for each section of the roads, depending on the type and amount the of the distresses, as well as the maintenance and rehabilitation required activity, by using the Cost-Effective Pavement Preservation Solutions for the Real-World book [15], we can easily calculate the maintenance and rehabilitation cost for each section of the roads. All the costs are in an Afghani currency with an exchange rate of $1 \$=70$ Afghani (08/Jan/2018).

Table II shows the criteria values or the decision matrix for all road sections, which we achieved from the above steps while we obtained the decision matrix by calculating weights.

The next step is to calculate the weight of the decision matrix for the prioritization process. For this purpose, we perform the weighing calculation process using well-known Shannon entropy method [12] and MS Excel software. Table III shows the weight criteria for the prioritization.

TABLE II. DECISION MATRIX

\begin{tabular}{|l|l|l|l|l|l|l|l|}
\hline ID & $\begin{array}{l}\text { Road's } \\
\text { name }\end{array}$ & Sec. & PCI & TF & W & IF & Cost \\
\hline 1 & Shahid Rd & 1 & 100 & 11074 & 10 & 7.15 & 1,809 \\
\hline 2 & Shahid Rd & 2 & 99 & 11074 & 10 & 6.87 & 1,777 \\
\hline 3 & Sulh Rd & 1 & 99 & 10902 & 10 & 7.28 & 1,809 \\
\hline 4 & Sulh Rd & 2 & 98 & 10902 & 10 & 7.20 & 2,233 \\
\hline 5 & Sulh Rd & 3 & 99 & 10902 & 10 & 7.53 & 1,712 \\
\hline 6 & $\begin{array}{l}\text { Kulola } \\
\text { Pushta Rd }\end{array}$ & 1 & 95 & 7315 & 10 & 6.98 & 2,298 \\
\hline 7 & $\begin{array}{l}\text { Kulola } \\
\text { Pushta Rd }\end{array}$ & 2 & 92 & 7315 & 10 & 6.98 & 2,162 \\
\hline 8 & $\begin{array}{l}\text { Kulola } \\
\text { Pushta Rd }\end{array}$ & 3 & 95 & 7315 & 10 & 7.65 & 2,135 \\
\hline 9 & $\begin{array}{l}\text { Shahr e Naw } \\
\text { St }\end{array}$ & 1 & 100 & 1825 & 7.5 & 7.62 & 897 \\
\hline 10 & $\begin{array}{l}\text { Shahr e Naw } \\
\text { St }\end{array}$ & 2 & 100 & 1825 & 7.5 & 7.67 & 456 \\
\hline 11 & $\begin{array}{l}\text { Shahr e Naw } \\
\text { St }\end{array}$ & 3 & 100 & 1825 & 7.5 & 7.24 & 293 \\
\hline 12 & $\begin{array}{l}\text { Shahr e Naw } \\
\text { St }\end{array}$ & 4 & 100 & 1825 & 7.5 & 7.65 & 1,223 \\
\hline 13 & Ansari 1 St & 1 & 100 & 2030 & 8.5 & 7.55 & 978 \\
\hline 14 & Ansari 1 St & 2 & 94 & 2030 & 8.5 & 7.18 & 998 \\
\hline 15 & Ansari 2 St & 1 & 97 & 2120 & 8.5 & 7.13 & 2,517 \\
\hline 16 & $\begin{array}{l}\text { Ansari 2 St } \\
17\end{array}$ & 2 & 97 & 2120 & 8.5 & 6.98 & 2,130 \\
\hline 18 & Ansari 3 St & 1 & 100 & 2090 & 8.5 & 7.25 & 1,206 \\
\hline 19 & Ansari 3 St & 2 & 100 & 2090 & 8.5 & 7.05 & 1,141 \\
\hline 20 & Ansari 4 St & 2 & 98 & 3323 & 10 & 6.68 & 1,997 \\
\hline
\end{tabular}

TABLE III. WEIGHT CRITERIA FOR PRIORITIZATION

\begin{tabular}{|l|l|l|}
\hline Criteria & Weights & Mark \\
\hline PCI & 0.0009 & + \\
\hline Traffic volume & 0.7279 & + \\
\hline Width & 0.0175 & + \\
\hline IF & 0.0029 & + \\
\hline Cost & 0.2508 & - \\
\hline
\end{tabular}

\section{B. Road Maintenance Activity Prioritization}

After obtaining the decision matrix values and the weights table, it is time to use the MRAP tool to prioritize the alternatives. Therefore, by entering the values of the criteria, the decision matrix will be formed, we enter the values of the weights table and identify the negative weights. Subsequently, the software begins to calculate the TOPSIS model to prioritize alternatives based on the closeness coefficient of the ideal solution. Finally, an optimized prioritization table is being prepared. Now we can export the table to different formats for use in GIS platform to prepare the desired thematic maps. Table IV shows the roads maintenance and rehabilitation activity prioritization.

TABLE IV. PRIORITIZING ROADS USING MRAP TOOL

\begin{tabular}{|l|c|c|c|}
\hline \multicolumn{1}{|c|}{ Road's name } & Sec. & $\begin{array}{c}\text { Closeness } \\
\text { coefficient }\end{array}$ & Ranking \\
\hline Sulh Rd & 3 & 0.8483 & 1 \\
\hline Shahid Rd & 2 & 0.8463 & 2 \\
\hline Shahid Rd & 1 & 0.8428 & 3 \\
\hline Sulh Rd & 1 & 0.8394 & 4 \\
\hline Sulh Rd & 2 & 0.8040 & 5 \\
\hline Kulola Pushta Rd & 3 & 0.5607 & 6 \\
\hline Kulola Pushta Rd & 2 & 0.5599 & 7 \\
\hline Kulola Pushta Rd & 1 & 0.5552 & 8 \\
\hline Shahr e Naw St & 2 & 0.2311 & 9 \\
\hline Shahr e Naw St & 3 & 0.2154 & 10 \\
\hline Ansari 4 St & 1 & 0.2029 & 11 \\
\hline Shahr e Naw St & 1 & 0.1669 & 12 \\
\hline Ansari 1 St & 1 & 0.1634 & 13 \\
\hline Ansari 1 St & 2 & 0.1610 & 14 \\
\hline Ansari 3 St & 2 & 0.1493 & 15 \\
\hline Ansari 3 St & 1 & 0.1448 & 16 \\
\hline Shahr e Naw St & 4 & 0.1368 & 17 \\
\hline Ansari 4 St & 2 & 0.0693 & 18 \\
\hline Ansari 2 St & 2 & 0.0539 & 19 \\
\hline Ansari 2 St & 0.0295 & 20 \\
\hline
\end{tabular}




\section{Thematic Maps Preparation}

Finally, after finalizing all the data collection \& analysis, preparing decision matrix as well as weight table and prioritizing the maintenance and rehabilitation activity prioritization, it is time use all this information and produces the thematic maps in order to have a visual illustration of our study area. For doing this, we used the ArcGIS 10.4. Fig. 5 to 8 shows the thematic maps for various information.

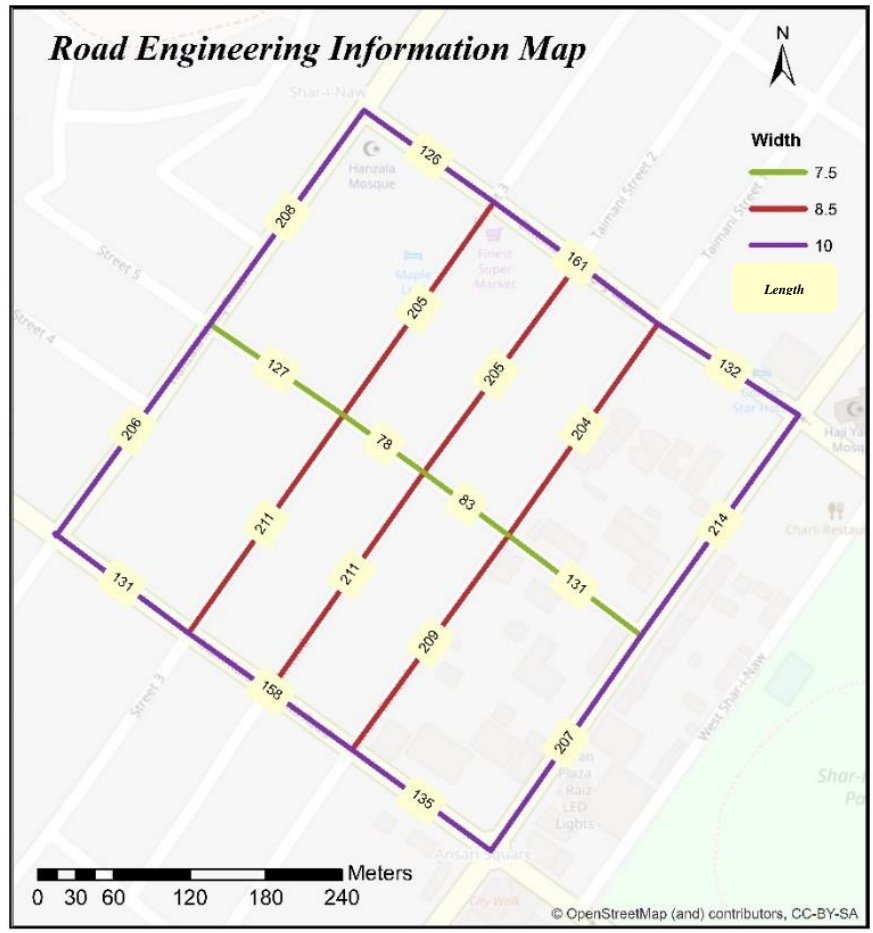

Fig. 5. Road engineering information map.

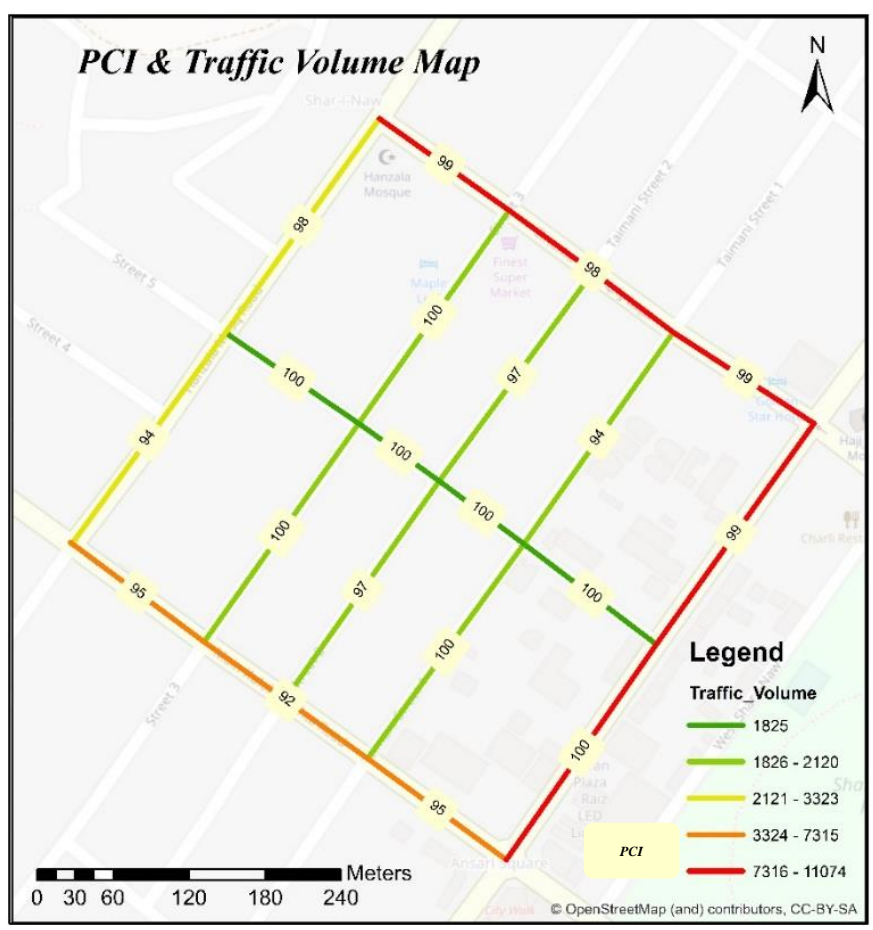

Fig. 6. Roads PCI and traffic volume map.

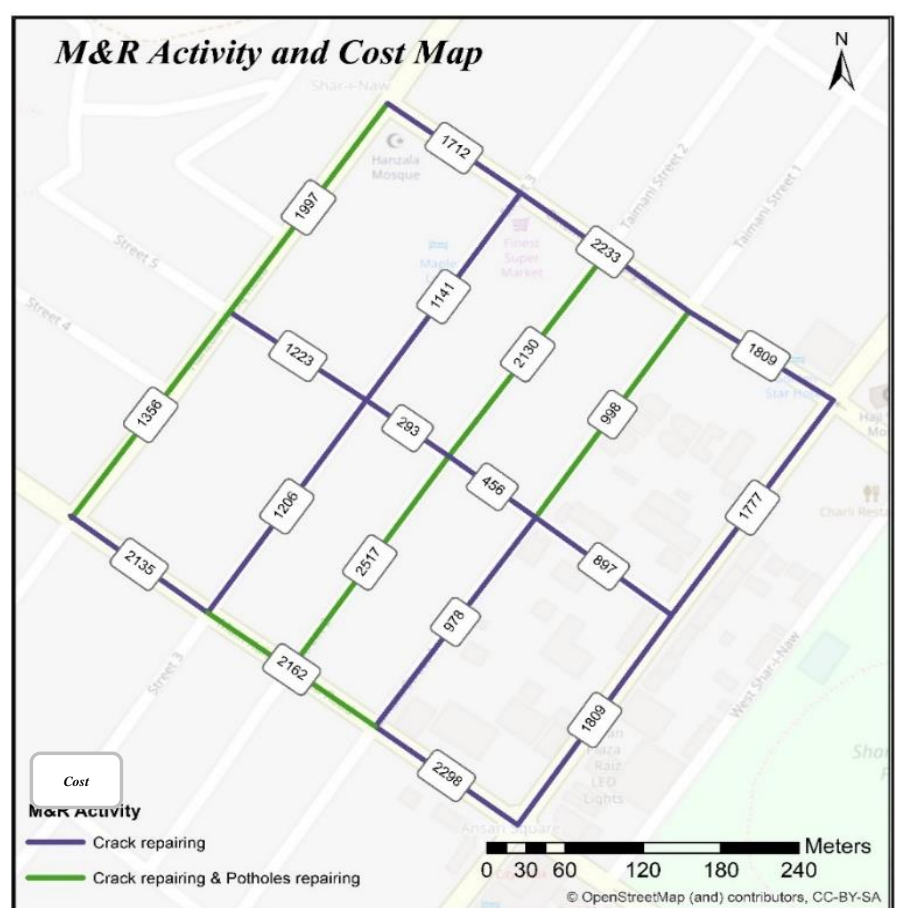

Fig. 7. Roads maintenance and rehabilitation and cost map.

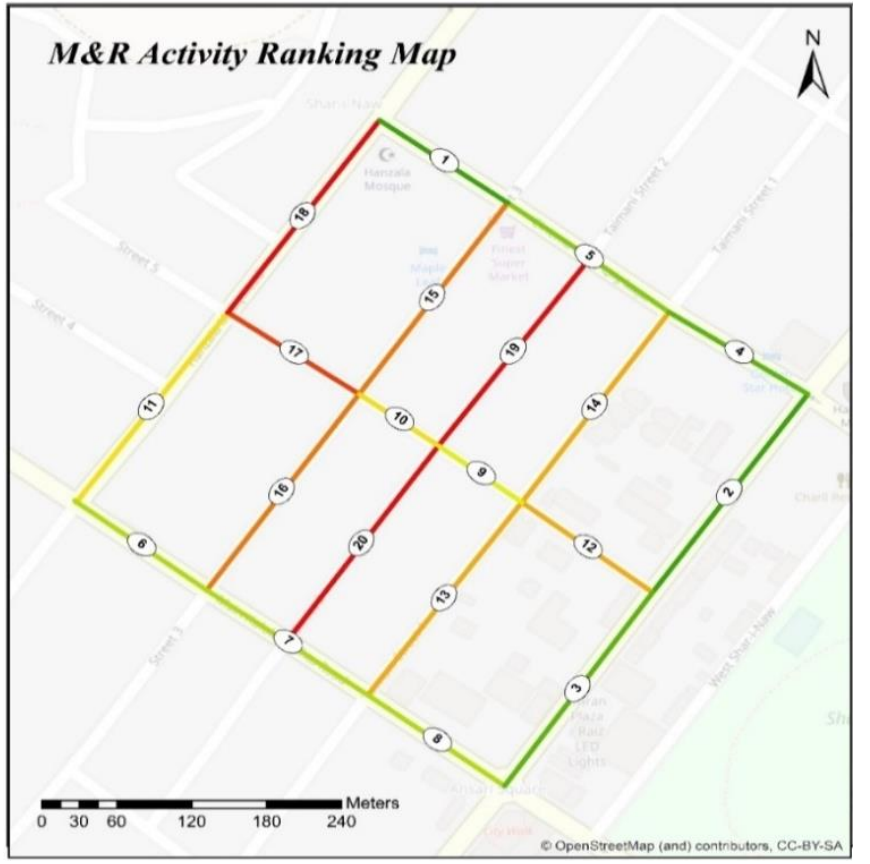

Fig. 8. Roads maintenance and rehabilitation activity ranking map.

\section{Results}

The results show that all roads are in a good condition, with minor distresses, which, with a low budget and small maintenance activities, could return to the ideal situation. In addition, according to the results, the traffic volume on secondary roads is way more than the residential roads.

The experiment has shown that GIS software has the capability to visually display the results, which enables the decision makers to better understand the area and make better 
decisions. The results also show that the MRAP tool, with a very simple process and the least resources, to prioritize maintenance activities can be a reliable tool with valid and reliable results.

According to the results, from all the criterion (PCI, width, traffic volume, IF and $M \& E$ cost) the $M \& E$ cost has a negative impact on our selection, means that, lower the cost is better for selection. While the other criterion is having a positive impact, means that the higher the values are better for our selection.

According to the results obtained, among all the alternatives the Sulh $\mathrm{Rd}$, section 3, among the other top priority options, with a small margin, ranked first to be carried out due to the low cost of M\&R activity, 1,712 Afghani accordingly.

From the experiments carried out, we conclude that the decision-making stage and setting of criteria for prioritizing maintenance activities are very important. That is, to the extent that the criteria are precise and decisive, as well as the ideal and valid results are obtained.

\section{CONCLUSIONS}

In this case study, the main goals were to prioritize the maintenance and rehabilitation activity as well as demonstrating all the outcomes through thematic maps by using the ArcGIS software. We conclude the results and outcomes of our case study as below:

- There is a total of $3,297 \mathrm{~m}$ roads in our study area, from secondary and residential classifications, $1,633 \mathrm{~m}$ and $1,664 \mathrm{~m}$ respectively.

- There are 20 roads (alternatives) with five criterions (pavement condition index, roads width, road traffic volume, political, social \& cultural importance factor and maintenance and rehabilitation activities costs) for prioritizing the maintenance and rehabilitation activities.

- Survey inspections carried out in order to collect the distress information from the roads for calculation of the PCI. The Paver 5.2 (demo version) used for calculating the PCI.

- The political, social and cultural importance factor questionnaire has been developed and ten experts gave their idea for scoring the roads importance factor. Later, by using Ms. Excel software and by averaging up expert opinions, the final score for important factor was calculated.

- For obtaining the costs for maintenance activities, Ms. Excel software and the Cost-Effective Pavement Preservation Solutions for the Real-World book were used, which the total cost of maintenance in the study area is a total of AFN 31,127.

- To obtain the weights for the decision matrix, the famous Shannon Entropy method and Excel software were used.
- For prioritizing the maintenance and rehabilitation activities, the MRAP tool was used, which had reliable outcomes. Also, to use this tool, at least $2+$ alternatives are required with more than two criteria.

- The integration of the TOPSIS model, as a multi-criteria decision-making method, can be used to optimize/rank the maintenance activities.

- Various thematic maps produced using ArcGIS 10.4, by using all the outcomes of the case study.

\section{ACKNOWLEDGMENT}

The Authors would like to thank from the University of the Ryukyus, Japan International Cooperation Agency (JICA) Project for the Promotion and Enhancement of the Afghan Capacity for Effective Development (PEACE) for providing found and giving a chance for the improvement of knowledge scales and the government of Afghanistan for its cooperation in this study.

\section{REFERENCES}

[1] "Ministry of Public Work," MoPW, [Online]. Available: https://www.mopw.gov.af/fa. [Accessed 23 March 2017].

[2] "The World Road Association," PIARC, [Online]. Available: https://www.piarc.org/en/. [Accessed 23 March 2017].

[3] "Sacramento County Department of Transportation," SACDOT, [Online]. Available: https://www.sacdot.com/Pages/default.aspx. [Accessed 23 March 2017].

[4] E. A. Sharaf and F. M. Mandeel, "An Analysis of The Impact of Different Priority Setting Techniques on Network Pavement Condition," 4th International Conference on Managing Pavements, vol. 1, pp. 158-168, 1998.

[5] C. Hwang and K. Yoon, Multiple Attribute Decision Making: Methods and Applications a State-of-the-Art Survey, New York: Springer, 1981.

[6] K. Yoon, "A Reconciliation Among Discrete Compromise Solutions," Journal of the Operational Research Society, vol. 38, no. 3, pp. 277-288, 1987.

[7] Y. L. a. T. L. C.L. Hwang, "A new approach for multiple objective decision making," Computers \& Operations Research, vol. 20, no. 8, pp. 889-899, 1993

[8] T. M. a. E. A. A. Assari, "Role of public participation in the sustainability of historical city: usage of TOPSIS method," Indian Journal of Science and Technology, vol. 5, no. 3, pp. 2289-2294, 2012.

[9] K. Y. a. C. Hwang, Multiple Attribute Decision Making: An Introduction, California: SAGE Publications, 1995.

[10] A. Z. a. J. A. E.K. Zavadskas, "Evaluation of Ranking Accuracy in MultiCriteria Decisions," Informatica, vol. 17, no. 4, pp. 601-618, 2006.

[11] R. D. J. L. a. B. E. R. Greene, "GIS-Based Multiple-Criteria Decision Analysis," Geography Compass, vol. 5, no. 6, p. 412-432, 2011.

[12] D. Shi-fei and S. Zhong-zhi, "Studies on incidence pattern recognition based on information entropy," Journal of Information Science, vol. 31, no. 6, pp. 497 - 502, 2005.

[13] J. I. C. A. (JICA), "Draft Kabul City Master Plan; Sector Report 05: Transport Infrastructure Development Plan," RECS International Inc., Tokyo, 2011.

[14] J. I. C. A. (JICA), "The Study for the Development of the Master Plan for the Kabul Metropolitan Area in the Islamic Republic of Afghanistan; Final Report, Sector Report 8: Transportation," RECS International Inc., Tokyo, 2009.

[15] W. J. Wilde, L. Thompson, and T. J. Wood, Cost-Effective Pavement Preservation Solutions for the Real World, Minnesota: Department of Transportation, Research Services \& Library, 2014. 